\title{
Automation of QFD an e-Learning Tool for Product Development with an Integrated Product Data Management Platform in e-Business
}

\author{
Norman Gwangwava and Samson Mhlanga
}

\begin{abstract}
Quality Function Deployment (QFD) initially evolved from manufacturing organizations, but over the time has found applications in services of various kinds. QFD falls under the six strategies for new product development, notably, design for six sigma, stage-gate model, flexible product development, new concept development model, user-centered design. The evolution of the QFD concept preceded the overwhelming use of the computer in daily business conduct. As the computer continues to gain momentum as a central hub for daily business transactions, there is need to speed up the development of systems that are centered on the modern computer world. This paper shows a software development process for QFD automation. The automation is integrated within a Product Data Management (PDM) platform. The motivation towards this effort is to facilitate in-class demonstrations of the QFD methodology and also enable same paced development of product development systems. Product development systems such as PDM, Product Lifecycle Management (PLM) systems need to be intertwined with tools that enhance the development effort. Software based on VB 2005 was developed that allows interaction with the user through a graphical interface. The software automatically constructs Houses of Quality (HoQ) to the fourth level. A Microsoft Access database was used as the system backbone and linked to the AutoCAD 2010 software. The database keeps product data, customer requirements and technical requirements. Drawing files for the product were handled by the CAD module integrated with QFD and PDM system. Such a system is dynamic for e-Learning purposes since scholars can use any desired practical design task rather than a pre-modeled video that only supports the original design problem.
\end{abstract}

Index Terms - Computer aided design (CAD), e-Learning, product data management (PDM), quality function deployment (QFD).

\section{INTRODUCTION}

The paper is intended to illustrate development of an automated version of quality function deployment (QFD) to facilitate e-Learning as well as actual product development work within an integrated product data management (PDM) platform. Often, it is deemed as difficult to construct the QFD house of quality and perform the related calculations, especially by its potential users in the services industry like

Manuscript received November 9, 2011; revised December 20, 2011.

N. Gwangwava and S. Mhlanga are with the Department of Industrial and Manufacturing Engineering, National University of Science and Technology, P. O. Box AC 939, Ascot, Bulawayo, Zimbabwe (e-mail: eng.normie@ gmail.com).

S. Mhlanga is also $\mathrm{PhD}$ student in the Faculty of Engineering and the Built Environment, University of Johannesburg, South Africa (e-mail: smhlanga126@gmail.com). education, healthcare, and government [1]. The integration improves the quality and efficiency of the design process. The system can be used for class demonstrations on the computer and is also suitable for use by product development teams in a collaborative design approach. Literature on QFD concept, computer aided design (CAD) and product data management system (PDM) was considered to support the development of the tool. The design process is articulated in the methodology section. In conclusion the paper illustrated the system developed through samples of screen dumps and output tables.

\section{LITERATURE REVIEW}

\section{A. The Concept of e-Learning}

E-learning indicates a radical change in learning paradigm [2]. Furthermore, in comparison to traditional learning process in e-learning participants need to have several characteristics, such as self-motivation and self-discipline that contribute to success in e-learning process [3]. These features make e-learning a viable learning option. E-learning applications and processes include Web-based learning, computer-based learning, virtual classrooms and digital collaboration. Content is delivered via the Internet, intranet/extranet, audio or video tape, satellite TV, and CD-ROM. Intensive research on eLearning has been and is still being done. Research on evaluation and optimization of e-Learning Software Packages: Learning Object Repositories has been done [4]. Learning object (LO) is referred to as "any digital resource that can be reused to support learning" [5]. $L O$ repositories (LORs) are considered here as properly constituted systems (i.e., organized Los collections) consisting of LOs, their metadata and tools / services to manage them [6]. Metadata is considered here as "structured data about data" [7]. This paper extends the modern research effort on the subject of e-Learning towards developing learning objects to enhance students' e-learning in the subject of product development. In the process of building the learning resources, the paper presents the terminology of product design and development.

\section{B. Product Design}

Product design is the process of defining all of the companies' product characteristics [8]. The process must support product manufacturability (the ease with which a product can be made). Product design defines a product's characteristics which are appearance, materials, dimensions, tolerance, and performance standards. 
The generic product development process consists of six phases. The process begins with a planning phase, which is the link to advanced research and technology development activities. The conclusion of the product development process is the product launch where the product becomes available for purchase in the market. The complete six phases are as follows [9];

- $\quad$ Phase 0: Planning

- $\quad$ Phase 1: Concept development

- $\quad$ Phase 2: System-level design

- $\quad$ Phase 3: Detail design

- $\quad$ Phase 4: Testing and refinement

- $\quad$ Phase 5: Production ramp-up

\section{Quality Function Deployment}

QFD is a customer-driven planning process to guide the design, manufacturing, and marketing of goods [10]. At the strategic level, QFD presents a challenge and an opportunity for top management to break out of its traditional narrow focus on "results," which can only be measured after the fact, and to view the broader process of how results are obtained. Under QFD, all operations of a company are driven by the voice of the customer, rather than by edicts of top management or the opinions or desires of design engineers.

QFD benefits companies through improved communication and teamwork across all constituencies in the production process, such as between marketing, design, manufacturing, purchasing and suppliers. Product objectives are better understood and interpreted during the production process. Use of QFD determines the causes of customer dissatisfaction, making it a useful tool for competitive analysis of product quality by top management. Productivity as well as quality improvements generally follow QFD. More significantly, QFD reduces the time for new product development, and allows companies to simulate the effects of new design ideas and concepts. Some work highlighted the application of Data Quality within QFD but did not have an integrated approach [11]. Other researches on the subject of QFD include development of a fuzzy nonlinear model for quality function deployment considering Kano's concept [12], development of a mixed integer linear programming model for product development using QFD [13], and a fuzzy group decision-making approach in QFD [14].

\section{Computer Aided Design}

Technical drawing is the major design method by which ideas about the shape, form, dimensions, materials, machining methods and finishes of articles being made or constructed are passed between those working in the manufacturing and building industries. There are many CAD software packages available at the present day for use on a computer. For the purpose of describing CAD, we will only deal with AutoCAD. This software is capable of producing any technical drawing, no matter how complicated in the hands of a skilled operator.

AutoCAD drawings are actually mathematical databases. The position of each object in a drawing is stored as a co-ordinate in a database. The database is then translated into an image on the screen. AutoCAD is a general purpose Computer Aided Design program to prepare and store a wide variety of two-dimensional (2-D) drawings and three-dimensional (3-D) models [15]. It will increase speed and accuracy as compared to traditional methods.

\section{E. Product Data Management Systems (PDM)}

Product data management (PDM) systems are file repositories or "vaults" that hold mechanical CAD files, including parts and assembly models as well as drawing files [16]. The PDM vault allows mechanical engineers to better manage the complex interrelationships between the part, assembly and drawing files. PDM or product information management (PIM) systems provide the tools to control access to and manage all product definition data. This environment is depicted in Fig 1. Research on intelligent $\mathrm{CAD} / \mathrm{CAPP} / \mathrm{CAM} / \mathrm{CNC}$ Integration is explored in [17].

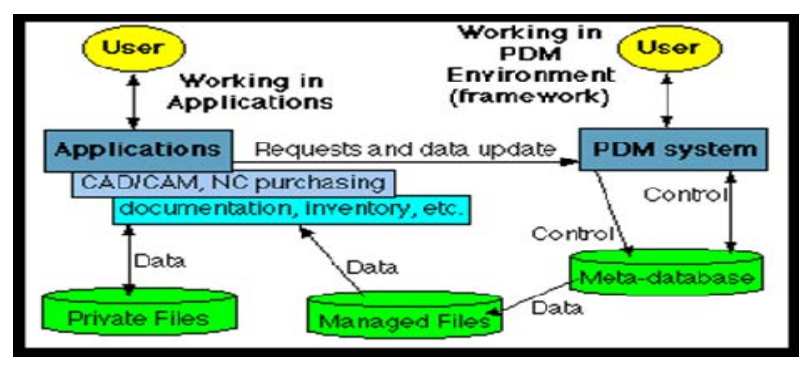

Fig. 1. Product data management environment.

\section{Methodology}

\section{A. Information Flow Model in Concurrent Innovation, Design, and Development.}

A synchronized information flow diagram that depicts the integrated approach which is the major thrust of the project was proposed. The flow diagram captures activities and functions that must be accomplished in the design and manufacture of a product, referred to as the Product Cycle. The design process starts from customer's demands and ends with a complete description of a product, usually in the form of a drawing. The synchronized information flow model is illustrated in Fig. 2.

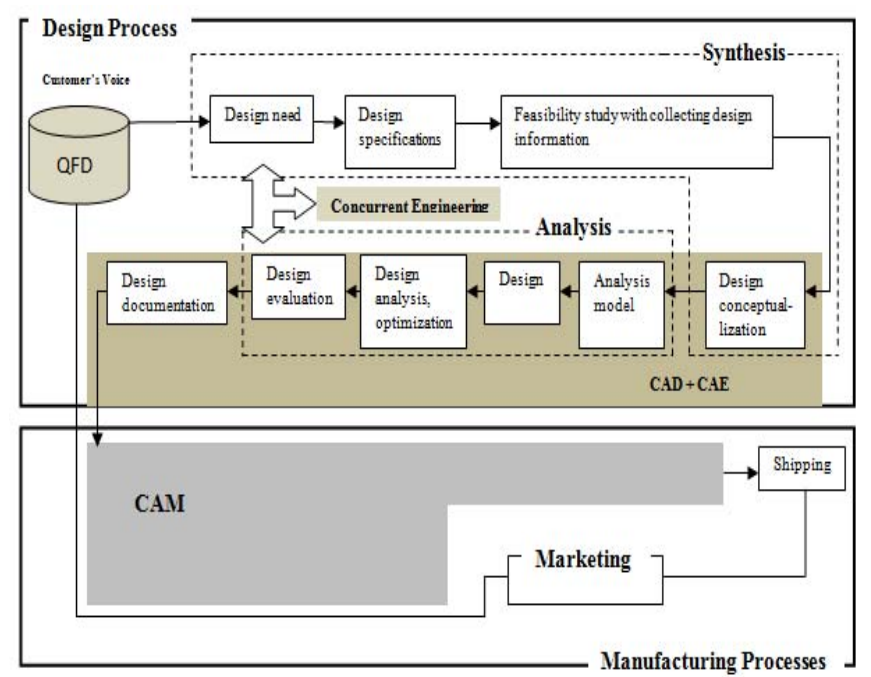

Fig. 2. A synchronized information model for concurrent innovation, product design and development. 


\section{B. Database Design}

QFD uses cross-functional teams to identify, understand and document unrealized knowledge involved in planning products, processes, services and strategies which become better than what the competition has to offer. A central database is the backbone of an integrated CAD, QFD and PDM. The designed system database was built on Microsoft Access system.

The database was modeled using the Entity Relational (ER) approach [18]. Relationships ensure a smooth data flow within a system. They maintain consistency of data entry into the system. Various system tables are linked together through the foreign and primary keys.

\section{Configuring the Database within AutoCAD}

This task can be accomplished directly through the command entry- dbConnect or through the system menu as follows [15]:

$>$ Choose Tools $>$ dbConnect to open the dbConnect palette and display the dbConnect menu.

The dbConnect Manager- Provides the primary interface for the connectivity feature. One can view and edit database tables, execute structured query language (SQL) queries, and link table records to graphical objects. By default, the dbConnect Manager opens as a docked window on the left side of the drawing area. The dbConnect Manager includes the following components:

- dbConnect Manager Buttons

- dbConnect Manager Tree View

- Drawing Nodes Shortcut Menu

- Database Objects Shortcut Menu

- Data Sources Node Shortcut Menu

- Data Objects Shortcut Menu

Fig. 3 shows the dbManager with unconnected databases, as indicated by an ' $\mathrm{X}$ ' in the lower right corner of each database and data object.

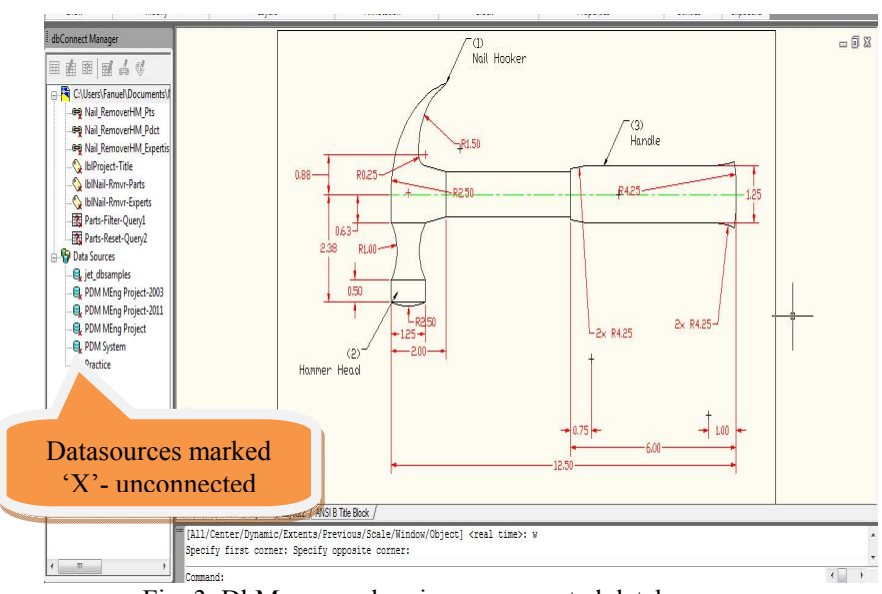

Fig. 3. DbManager showing unconnected databases.

Right-Clicking a data source, for instance (PDM MEng Project-2011) gives a tree-view of the tables associated with the data source. The entire database structure is now connected, and one can view and work with the database data within AutoCAD. Fig 4 shows the database structure connected by the 'PDM MEng Project-2011' data source.

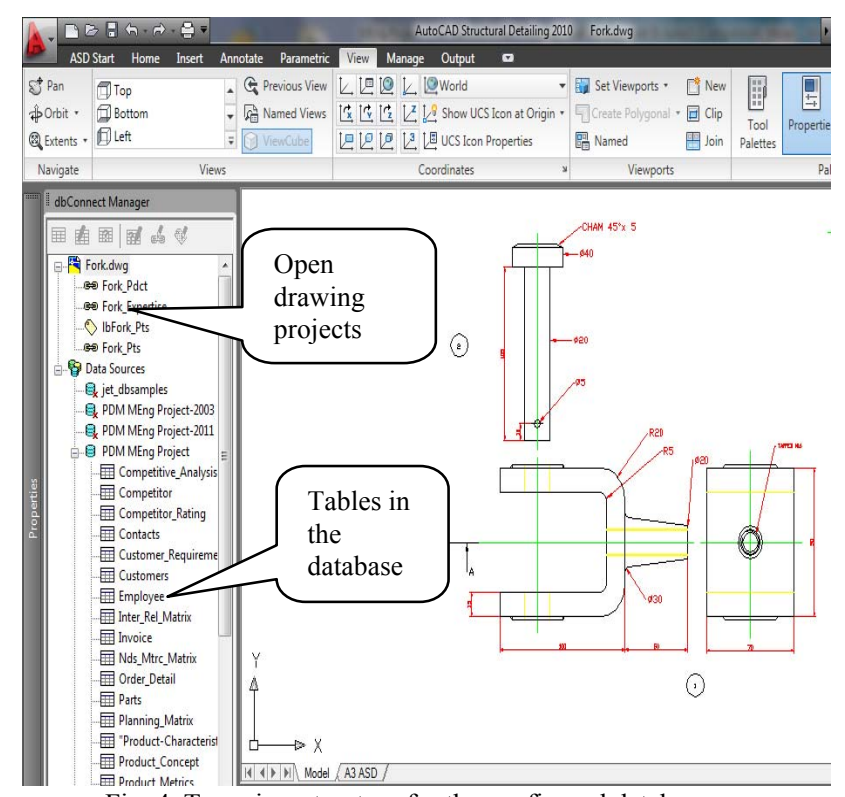

Fig. 4. Tree view structure for the configured database.

Fig. 4 shows three open projects; Fork, Hammer concept 1 and Rod clamp. The opened database tree view shows all the tables that make up the system database.

\section{Graphical User Interface (GUI) Design}

The user interface was designed using forms. Forms are user friendly and help in integrating the entire system [19]. The main form (parent) has menu options that manipulate all the other modules of the system.

VB 2005 was used to design the front-end system. VB 2005 connects to a database using data bound controls, in conjunction with the data objects. This allows us to view information in the database. Data objects fall in one of five categories:

$\Rightarrow$ Connections allow a program to connect to a database

$\Rightarrow$ Data containers hold data after it has been loaded from a database.

$\Rightarrow$ Data adapters move data between databases and containers

$\Rightarrow$ Command objects allow manipulation of the data

$\Rightarrow$ Navigation objects allow a user to move through (and also modify) data

Fig. 5 illustrates database connectivity in VB 2005.

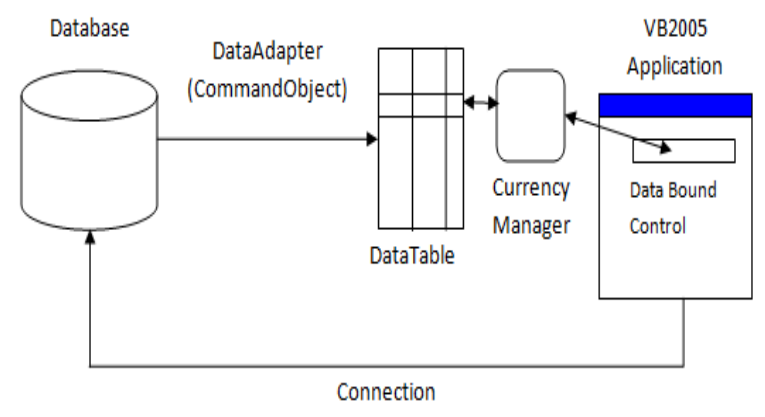

Fig. 5. Database connectivity in VB 2005.

\section{E. QFD Decision Module}

The software incorporates a decision module, rather than a single House of Quality (HoQ). The decision module can set 
up and interlink a collection of lists, matrices, and documents to construct a decision making model for a project [16]. This decision making model can be high level (a single HoQ) or detailed (many HoQs cascaded from one to another). The QFD decision model enable users to collect, analyze and manage qualitative data to give an accurate understanding of the company's competition space, customer expectations, and business needs. Microsoft Excel was used as the development platform for generating the QFD matrices. The matrices are designed as templates with multiple links to automate the subsequent generation of Houses of Quality (HoQs). These excel templates easily allow users to obtain print-outs and work with blank chart templates which are useful as documents-in-progress during team meetings.

\section{RESULTS}

\section{A. System Interface}

Fig. 6 shows a screenshot of the main user interface. It acts like a control panel that holds all the keys which the user needs in order to access functions of the system. The parent form has all the menu options that call all other forms needed by users who are working with the system. It also links the user to other two main application programs necessary for the complete functionality of the system, notably, AutoCAD and Excel.

In most learning environments, the application systems that make up the designed program are the basic tools normally used. Subject content for product design and development, engineering design normally bear aspects of geometric modeling by graphics software such as AutoCAD. Microsoft excel is also highly used for spreadsheet based computations and graphical work. This lessens the end user's burden in acquiring extra add-on programs to enable them to use the package as a tool in computer based learning. There is no need also to buy visual basic programming software since the program can be packaged for redistribution.

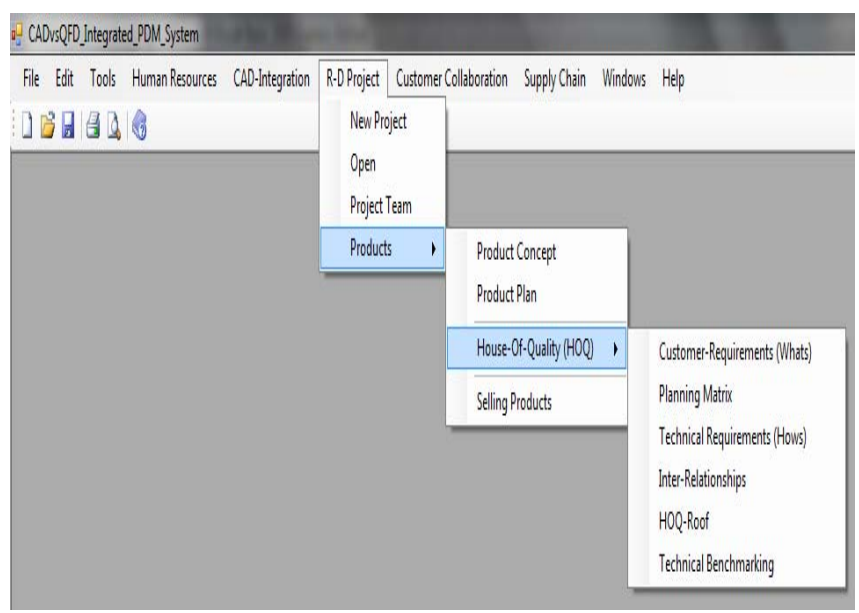

Fig. 6. System parent form.

\section{B. CAD Integration}

AutoCAD is used to facilitate the integration. CAD drawings are linked to the database and such connectivity allows data exchange between the two systems.
The dbConnect Manager shows currently open projects, links for the drawing objects, label templates, Queries, and data sources. The data sources can be expanded to show the complete database structure. The user can view records linked to objects by selecting the object followed by choosing the "view linked records" option. AutoCAD highlights the data row as shown in Fig. 7.

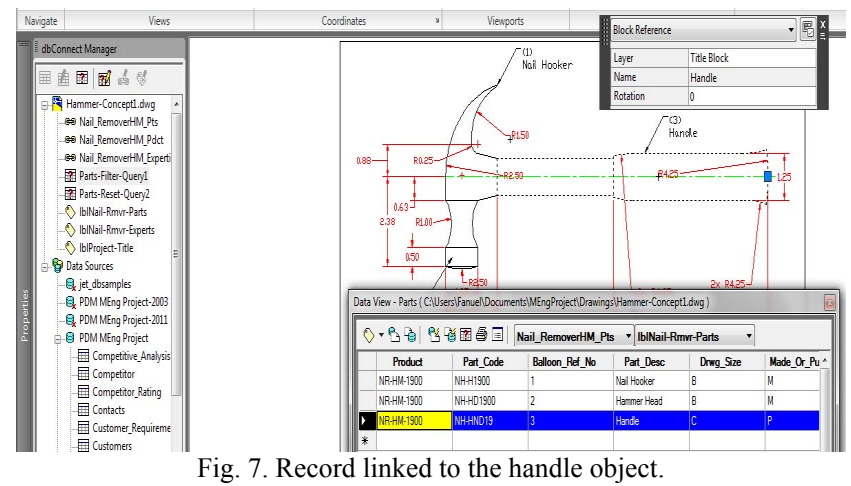

\section{Research and Development Module (R-D Project menu)}

The module is accessed through the menu option ' $R-D$ Project'. It consists of sub-menu options, New Project, Open, Project Team, Products and several pull-down menu options under the products sub-menu. This is where one finds the 'house-of-quality (HoQ)' sub menu that links to all procedures required to capture data relevant to the construction of the HoQ report. The projects interface shown in Fig 8 is where users can record new projects as well as navigate through existing project, in progress and shelved projects.

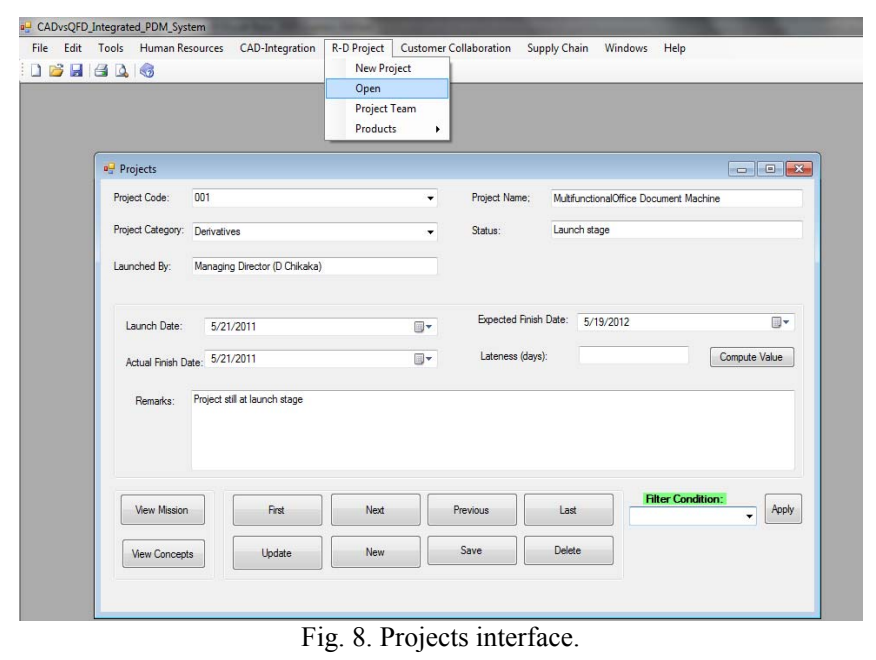

A range of filter conditions can be applied to the available projects in order to narrow down the user's range of view. The filter options are shown on the screenshot in Fig. 9.

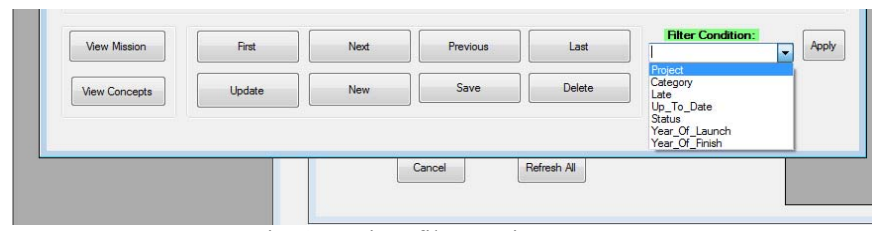

Fig. 9. Project filter options. 
The user can launch into the project mission interface straight from the project interface. For existing projects, this action will reveal the mission of the current project being viewed but in the case of new projects, this will present the user an opportunity to define the mission of the new project. The user can also call the product concept interface where they will gain access to AutoCAD files for different concepts about a particular product. Fig 10 shows the project mission interface for the current project ' 001 '.

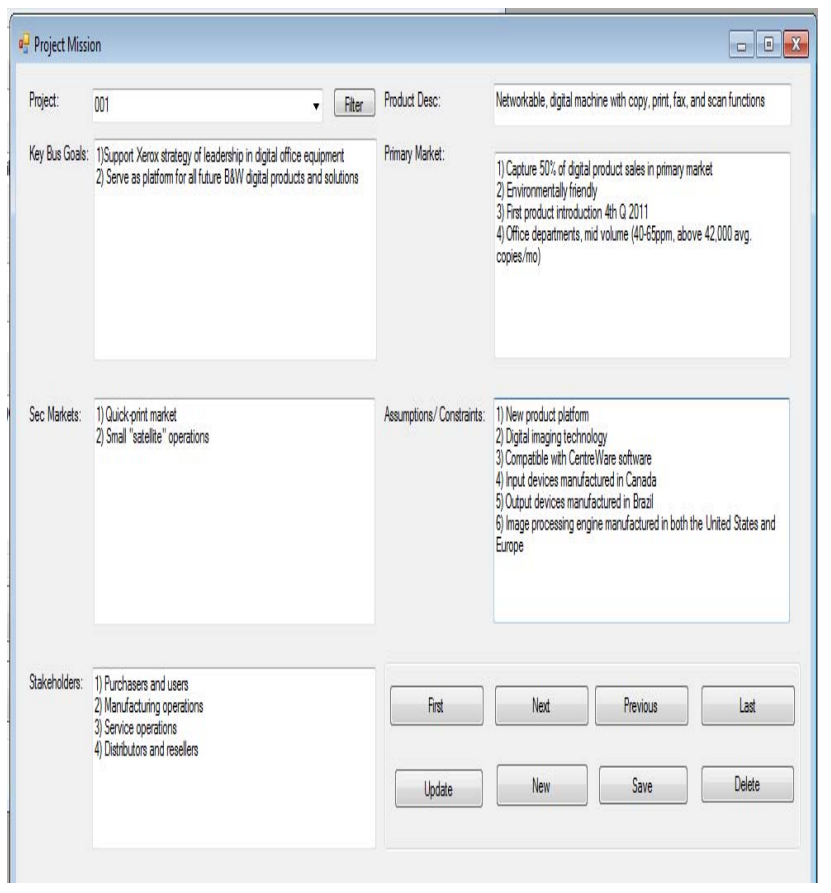

Fig. 10. Project mission interface.

The user also gains access to the project team interface that shows the team members for every project. There are various options presented to the user, such as filtering by project code, filtering by employee (viewing a range of projects where a particular employee participates), and adding new members to the project team.

\section{House of Quality}

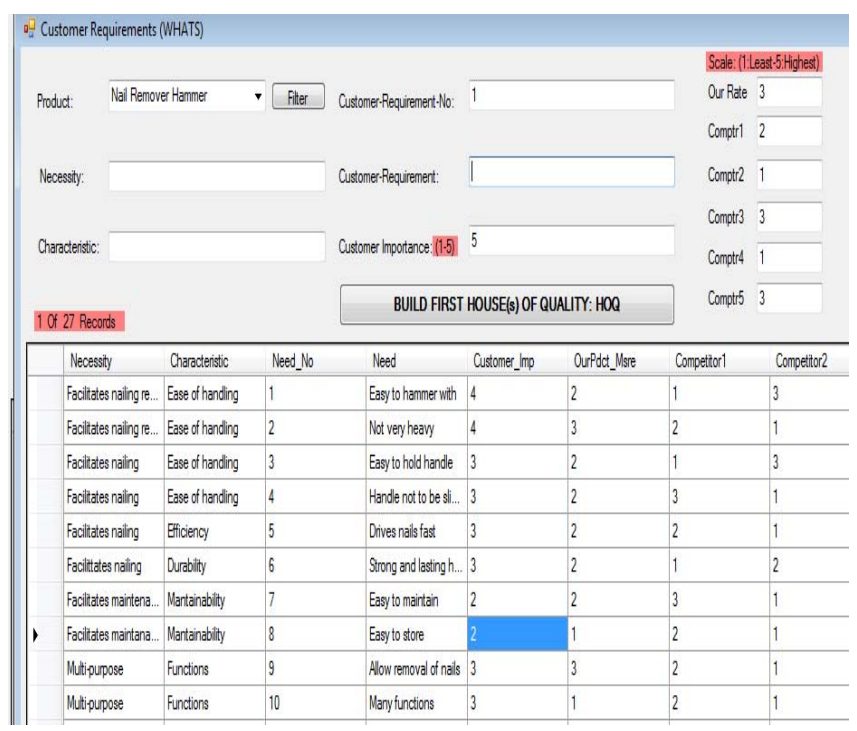

Fig. 11. Interface for building QFD matrix.
Due to the ability of the Ms Excel application to link cells together, the HoQ template automatically picks the customer requirements and builds a relationship matrix with the product metrics. The product metrics will be cascaded to form the first matrix in the second house of quality (HoQ2). Such cascading will continue until a satisfactory analysis is done for individual components making up a product. Unlike most QFD builders which are flash player based, such as the VOC/eQFD Tutorial [20], the approach taken in this platform uses a friendly interface for adding data about a product into the main database. The user can decide to build and view the QFD for the particular product by clicking the "Build First House(s) of Quality" button. Fig. 11 shows the interface for entering product data into the main system. A complete HOQ is shown in Fig. 12.

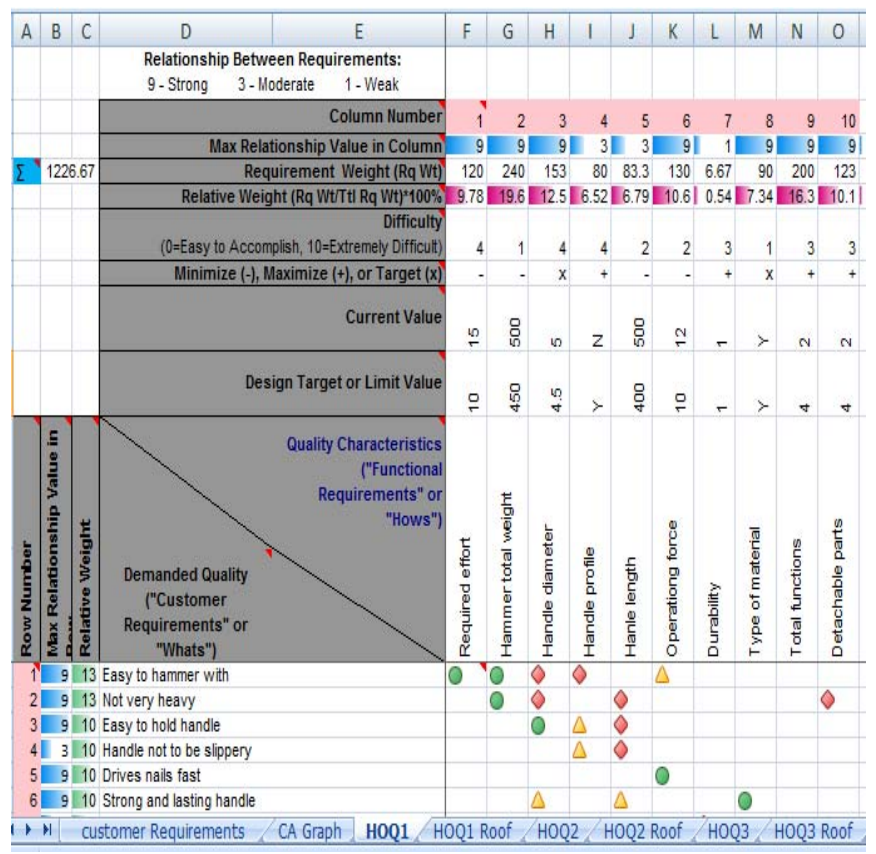

Fig. 12. House of quality matrix.

\section{CONClusions And Future Work}

From an eLearning perspective, the integrated system provides a practical oriented learning approach. The program is flexible unlike other flash player based systems that are like watching a video which may end up boring. The proposed solution goes an extra mile to allow learners to develop their own products using the software. The user gets a complete visibility of the design process right through the end product without switching into other systems. The software package improves the speed of the whole design process through automation of tasks traditionally done manually like completing the HoQ templates. With advancements in the computer world, customer's voice can be tapped through internet connectivity and fed directly into the system for subsequent processing.

Future work should focus on taping advanced features of AutoCAD such as Internet tools and collaboration. These tools enable users to collaborate and share designs with colleagues and clients using internet technologies. AutoCAD now includes features that allow us to be more connected to Web technology by enabling capabilities, such as publishing 
Web pages that include drawings, emailing drawings, linking other remotely located drawings and documents to drawings, creating single drawings or complete drawing sets that are viewable in standard web browsers.

\section{REFERENCES}

[1] B. Kanishka, (2006), Automating the Quality Function Deployment House of Quality (November 1, 2006). U21Global Working Paper No. 011/2006. Available

http://www.u21global.com/portal/corporate/pdf/wp/2006/wp_011-200 6.pdf

[2] Y. K. Lee, S. P. Tseng, F. J. Liu, and S. C. Liu, "Antecedents of Learner Satisfaction toward E-learning," The Journal of American Academy of Business, 11(2), 161-168, 2007.

[3] K. Bose, "An e-learning experience - a written analysis based on my experience in an e-learning pilot project," Campus-Wide Information System, 20(5), 193-199, 2003.

[4] E. Kurilovas, "Evaluation and Optimization of e-Learning Software Packages: Learning Object Repositories," 2009 Fourth International Conference on Software Engineering Advances, IEEE-Computer Society, pp 477-483, 2009.

[5] D. A. Wiley, "Connecting Learning Objects to Instructional design Theory: a definition, a Metaphor, and a Taxonomy," Utah State University, 2000. [online], http://www.reusability.org/read

[6] E. Kurilovas, "Digital Library of Educational Resources and Services: Evaluation of Components," Informacijos mokslai (Information Sciences). Vilnius, vol. 42-43, pp. 69-77, 2007.

[7] E. Duval, W. Hodgins, S. Sutton, S. L. Weibel, "Metadata Principles and Practicalities," D-Lib Magazine, 2002, vol. 8, no 4. [online], http://www.dlib.org/dlib/april02/weibel/04weibel.html

[8] A. Yoji, "New product development and quality assurance - quality deployment system", Standardization and Quality Control, vol. 25 no. 4. pp. 7-14, 1972.

[9] T. U. Karl and D. E. Steven, 2003, Product Design and Development, $3^{\text {rd }}$ Edition, McGraw Hill

[10] X. A. Koufteros, M. Vonderembse, and J. Jayaram, "Internal and External Integration for Product Development: The Contingency Effects of Uncertainty, Equivocality, and Platform Strategy,' Decisions Sciences, vol. 36, no. 1, pp. 77-133, 2005.

[11] K. Wang, S. Tong, L. Roucoules and B. Eynard, "Analysis of consumer's requirements for data/information quality by using HoQ," Proceedings of the 2008, IEEE-IEEM, pp. 313-217, 2008.

[12] L. H. Chen, W. C. Ko, "A fuzzy nonlinear model for quality function deployment considering Kano's concept," Mathematical and Computer Modelling, vol.48, no.3-4, pp.581-593, 2008.

[13] E. K. Delice and Z. Güngör, "A new mixed integer linear programming model for product development using quality function deployment," Computers and Industrial Engineering, vol. 57, no. 3, pp.906-912, 2009.

[14] C. H. Liu and H. H. Wu, "A fuzzy group decision-making approach in quality function deployment," Quality and Quantity, vol. 42, no.4, pp.527-540, 2008

[15] E. Finkelstein, AutoCAD 2004 Bible, Wiley Publishing, Inc, 2003.

[16] T. Klee, SAP AG, (2006), Fully Integrate Product Design Into Your Business Processes for Faster Time-to-Market, vol. 7, April(Issue 2)

[17] X. W. Xu, H. Wang, J. Mao, S. T. Newman, T. R. Kramer, F. M. Proctor, and J. L. Michaloski, "STEP-Compliant NC Research: The search for Intelligent $\mathrm{CAD} / \mathrm{CAPP} / \mathrm{CAM} / \mathrm{CNC}$ Integration," International Journal of Production Research, vol. 43, pp. 3703-3743, 2005.
[18] K. S. Babu et. Al, "Development of a Manufacturing database System for Step-NC data from express entities," International Journal of Engineering Science and Technology, vol. 2, no.11, 2010, 6819-6828

[19] VB.Net, (2011),

http://visual-basic-dox.net/Prentice.Hall.PTR-An.Introduct/pindex.ht m (Accessed, 04/28/2011)

[20] http://www.qfdonline.com/qfd-tutorials/voc-and-e-qfd-tutorial/ (Accessed, 21/11/2011)

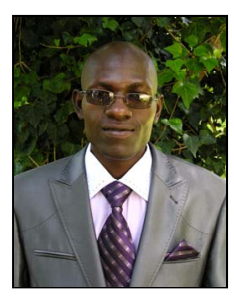

Norman Gwangwava is currently a TEMPORARY FULL-TIME LECTURER at the National University of Science and Technology (NUST), department of Industrial and Manufacturing Engineering in the faculty of Industrial Technology. He graduated with a Bachelor of Engineering honors degree in Industrial and Manufacturing Engineering at NUST in 2008 and later joined Willsgrove Ware Pottery until January 2009 as a post-graduate trainee in PRODUCTION MANAGEMENT before moving to Bulawayo Polytechnic as a LECTURER in the mechanical engineering division in July 2009-September 2010. He joined NUST in September 2010 as a TEACHING ASSISTANT and was upgraded to his current title after completing his Master of Engineering degree in Manufacturing Systems and Operations Management (MSOM) with NUST in November 2011. He published two papers: (1). N Gwangwava and S Mhlanga, (2011). "Design of an Integrated CAD and Quality Function Deployment (QFD) Product Data Management System (PDM)." $20113^{\text {rd }}$ International Conference on Advanced Management Science (ICAMS 2011), Vol. 19. pp. 165-169, ISBN: 978-981-08-9928-8.

(2). S Mhlanga, C Mbohwa, J H pretorius and N Gwangwava, (2011). "Review of Optimization Applications in Rail Freight Logistics with a View to Identify Possible Applications in the Southern Africa Region." $20113^{\text {rd }}$ International Conference on Advanced Management Science (ICAMS 2011), Vol. 19. pp. 119-125, ISBN: 978-981-08-9928-8.

His research interests are in the following areas; Reconfigurable Manufacturing Systems (RMS), Computer Integrated Manufacturing (CIM), and CAD/CAM.

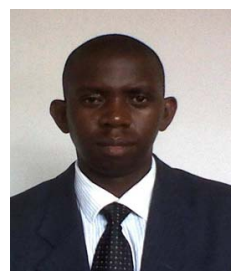

Samson Mhlanga is a SENIOR LECTURER with Zimbabwe National University of Science and Technology. Graduated with a Bachelor of Engineering degree in Industrial Engineering at NUST in 1996, Masters of Science in Advanced Manufacturing Systems at Brunel University in UK. He is currently a member of the Zimbabwe Institute of Engineers and Member of Southern African Institute of Industrial Engineers. Currently $\mathrm{PhD}$ student in Faculty of Engineering and the Built Environment at University of Johannesburg, South Africa. Research interests are modelling and simulation, product design, optimisation of rail freight using operations research and metaheuristics. 